\title{
SLOPE STABILITY ANALYSIS OF KALLAR-COONOOR HILL ROAD STRETCH OF THE NILGIRIS
}

\author{
${ }^{1}$ Nalina, P., ${ }^{2}$ T. Meenambal and ${ }^{3}$ R. Sathyanarayan Sridhar \\ ${ }^{1}$ Department of Civil Engineering, Avinashilingam University for Women, Coimbatore-641 108, Tamil Nadu, India \\ ${ }^{2}$ Department of Civil Engineering, Government College of Technology, Coimbatore-641 013, Tamil Nadu, India \\ ${ }^{3}$ Department of Civil Engineering, Coimbatore-641 014, Tamil Nadu, India
}

Received 2014-01-02; Revised 2014-01-03; Accepted 2014-02-04

\begin{abstract}
The stability of slopes is always under severe threats in many parts of Western Ghats, especially in KallarCoonoor hill road stretch, causing disruption, loss of human life and economy. To minimize the instability of soil slope in between Kallar-Coonoor, a critical evaluation of roads is required. The stability of slopes depends on the soil shear strength parameters such as Cohesion, Angle of internal friction, Unit weight of soil and Slope geometry. The stability of a slope is measured by its factor of safety using geometric and shear strength parameter based on infinite slopes. In this present study, investigation was carried out at 32 locations in the above said hill road stretch to estimate the factor of safety of the slope determined by MohrCoulomb theory based on shear strength parameter calculated from direct shear test which is a conventional procedure for this study. Back Propagation Artificial Neural Network (BP-ANN) Model is used to predict the factor of safety. The input parameters for the (BP-ANN) are chosen as Cohesion, Angle of internal friction, Density and Slope angle and the factor of safety as output. Out of the parameters of 32 locations, the study of BP-ANN is trained with parameters of first 25 locations. Factor of safety was calculated for the remaining 7 locations. The results obtained in BP-ANN method were compared with that of conventional method and observed a good agreement between these two methods. The results obtained from these two methods were also compared with the details of actual field Landslide occurred and indicates $71.4 \%$ of conventional method locations matching with the physical occurrences and $85.7 \%$ of BP-ANN predicted vulnerable locations match with the physically observed landslide locations.
\end{abstract}

Keywords: Slope Stability, Factor of Safety, Back Propagation, Artificial Neural Network (BP-ANN), Soil-Slope, Landslide

\section{INTRODUCTION}

Landslide is a frequently occurring natural phenomenon, especially in hilly area and it is defined as the natural or manmade failure of soil mass (Ganapathy et al., 2010). It occurs mainly in the hill slopes, embankment or cuttings of highway or railway and causing damages to human life and properties. The Kallar-Coonoor road stretch (National Highway No: 67) in Nilgiri District of Tamilnadu, India is severely affected by landslide in many locations in the years 1978, 1979, 1993, 2006, 2009 and 2011 caused damages to 'human life, properties and it is also a well known region for frequent landslide occurrence during monsoon almost every year (Terzaghi and Peck, 1967). There is no drainage system in this stretch which leads to progressive disintegration of the structure of the soil mass and results in landslide. Apart from the heavy rain fall, following factors such as Population increase, Infrastructure development, Land use, Land cover change and road widening process increases the possibility of landslide in this hill stretch many times (Manimaran et al., 2012; Ramasamy et al., 2006; Kumar and Bhagavanulu,

Corresponding Author: Nalina, P., Department of Civil Engineering, Avinashilingam University for Women,

Coimbatore-641 108, Tamil Nadu, India 
2008). There are two monsoons namely, Southwest (July-September), Northeast (October-December) yield a very good rainfall every year causing landslide in this stretch. In 2006 landslides were occurred nearly in 30 locations of the study area. The above said road stretch suffered soil slips, earth slides, rock falls and land subsidence, due to the fact that the road stretch is highly vulnerable because of steeper hill slope, become more unstable conditions against landslides. In the most of the locations landslides are prominent; the dip of the bed formation is greater than $60^{\circ}$. The area in which bed dip towards the slope with dip angle greater than $45^{\circ}$ are unsafe (Arora, 1988; Liang and Zhang, 2012; Neaupane and Achet, 2004) and more prone to landslide. These facts warrant a separate detailed scientific study on the slope stability of this road stretch. Hence, the study of slope stability is felt necessary especially in Ghats road sections (Ajaynaithani et al., 2002; GSI, 2000). In addition to that there are certain places where the slope angle is so critical which paves way for landslides. Since such landslides are prominent in the rainy seasons, this study aims to find out measures to maintain slope stability which reduces the chance of landslides.
A reconnaissance survey was conducted in the highway of Kallar to Coonoor road stretch about $27 \mathrm{~km}$ revealed that many slope are unstable. As a result of this observation, 32 locations were chosen and samples were collected to analyse the slope stability based on the parameters, such as Cohesion, Density, Angle of internal friction and Slope angle. The factor of safety was determined by Mohr's Coulomb theory as given in Equation (1) (Arora, 1988) and the obtained results were trained in Back propagation Artificial Neural Network (BP-ANN) for the prediction of slope stability. It was observed that factor of safety predicted by BP-ANN closely matches with physically occurred landslides.

\subsection{Study Area}

Nilgiris means "mountains in Blue Colour," is one of the most popular hill districts in India, situated in Western Ghats and the geographical location of the study area is shown in Fig. 1. It has picturesque hill stations such as Ooty, Coonoor and Kothagiri. The height of hill range varies between 2280 and $2290 \mathrm{~m}$ above Mean Sea Level (MSL).

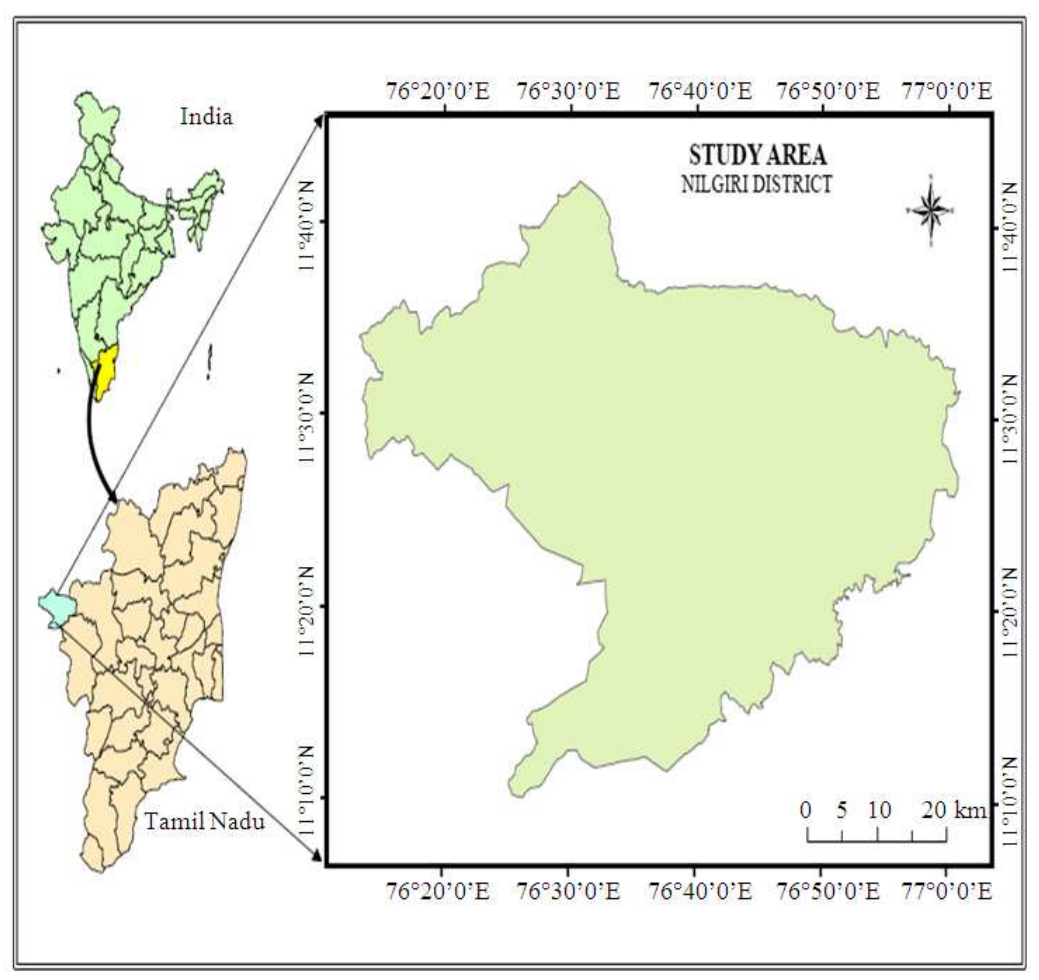

Fig. 1. Geographical location of study area 
The area lies between $11^{\circ} 8^{\prime} \mathrm{N}$ to $11^{\circ} 15^{\prime} \mathrm{N}$ latitudes and $76^{\circ} 13^{\prime} \mathrm{E}$ to $77^{\circ} 2^{\prime} \mathrm{E}$ longitudes, covering an area of $2593 \mathrm{sq}$. $\mathrm{km}$. The monthly average rainfall in the district is 94.20 $\mathrm{mm}$. The months of June, July, September, October and November receive a rainfall that is more than the annual average rainfall. The district has highest average number of rainy days with 7.3 days per month, Mean maximum average temperature of $20.7^{\circ} \mathrm{C}$, mean minimum average temperature of $9.6^{\circ} \mathrm{C}$ and mean relative humidity maximum of $76.9 \%$ and minimum of $75.8 \%$. In the previous history records, landslide were predominantly occurred mostly in Kallar to Coonoor road stretch.

\section{MATERIALS AND METHODS}

\subsection{Conventional Method of Slope Stability Analysis}

Geotechnical analysis was carried out in the road length of $27 \mathrm{~km}$ in a micro level basis and both the undisturbed and disturbed soil sample were collected from the 32 locations mentioned in Fig. 2. Slope of the road in each location was measured with Clinometer, nature of vegetation and location of landslide occurred area were recorded with the help of Global Positioning Systems (GPS). The major influencing factors for soil slope failure are Density, Cohesive, Angle of internal friction and Slope angle (Gopalaranjan and Rao, 1993).
Out of these, the three important factors such as density, angle of internal friction and cohesion were determined in the laboratory using undisturbed soil samples collected from the above locations. Direct shear test with $6 \times 6 \times 6 \mathrm{~cm}$ shear box has been performed over the samples to determine shear strength parameters under un-drained condition. The surcharge weight applied over the samples was equal to the amount of overburden existing at the site. The factor of safety of each location is calculated using Mohr coulomb theory with the infinite formula as given in Equation (1). The exact latitude and longitude of the sampling locations along with respective soil properties and factor of safety are presented in Table 1. In this, if value of factor of safety is $\geq 1$ represents stable condition of slope and $<1$ denotes unstable condition of slope:

$$
\mathrm{F}=\frac{\mathrm{C}+\gamma Z \operatorname{Cos}^{2} \beta \tan \theta}{\gamma Z \cos \beta \operatorname{Sin} \beta}
$$

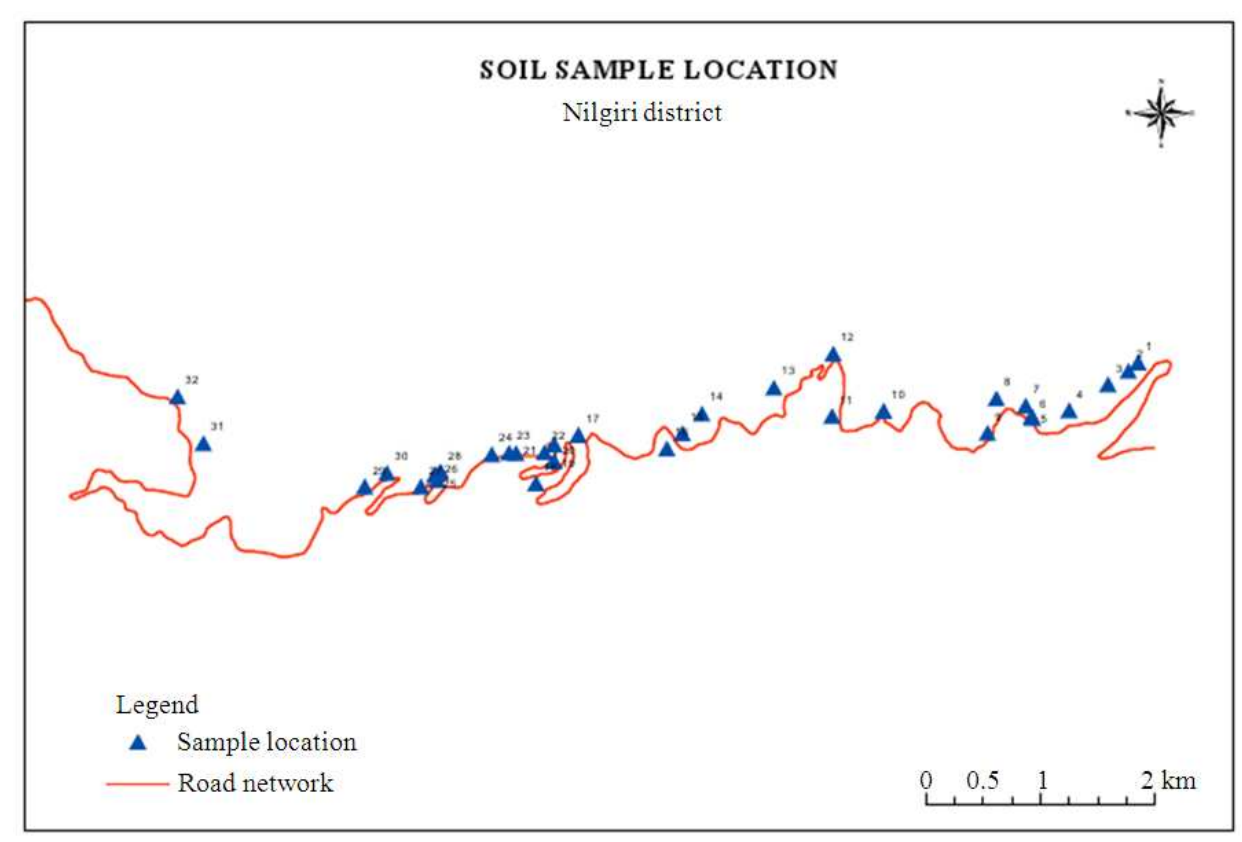

Fig. 2. 32 Sampling locations in Kallar-Coonoor hill road stretch 
Nalina, P. et al. / Journal of Computer Science 10 (7): 1107-1114, 2014

Table 1. Observed soil parameters and landslide occurrence

\begin{tabular}{|c|c|c|c|c|c|c|c|c|c|}
\hline \multicolumn{10}{|c|}{ Sample location } \\
\hline $\begin{array}{l}\text { Latitude } \\
(\text { degree } \mathrm{N})\end{array}$ & $\begin{array}{l}\text { Longitude } \\
\text { (degree E) }\end{array}$ & $\begin{array}{l}\text { Density } \\
\text { of soil } \mathrm{g} / \mathrm{cc}\end{array}$ & $\begin{array}{l}\text { Angle of } \\
\text { internal friction } \\
\text { in degree }\end{array}$ & $\begin{array}{l}\text { Slope in } \\
\text { degree }\end{array}$ & $\begin{array}{l}\text { Cohesion } \\
\text { in } \mathrm{g} / \mathrm{cm}^{2}\end{array}$ & $\begin{array}{l}\text { Factor of } \\
\text { safety }\end{array}$ & $\begin{array}{l}\text { Slope stability } \\
\text { as per soil } \\
\text { parameters }\end{array}$ & $\begin{array}{l}\text { Physically } \\
\text { observed } \\
\text { landslide }\end{array}$ & $\begin{array}{l}\text { Chance of } \\
\text { landslide } \\
\text { occurrence }\end{array}$ \\
\hline 11.344 & 76.874 & 1.45 & 36.5 & 41.0 & 4 & 0.89 & Instability & Not Occurred & Possible \\
\hline 11.343 & 76.873 & 1.33 & 53.3 & 64.0 & 0 & 0.65 & Instability & Occurred & - \\
\hline 11.342 & 76.871 & 1.35 & 48.8 & 57.5 & 0 & 0.73 & Instability & Occurred & - \\
\hline 11.34 & 76.868 & 1.40 & 40.8 & 62.0 & 46 & 0.83 & Instability & Occurred & - \\
\hline 11.339 & 76.865 & 1.61 & 27.4 & 38.5 & 7 & 0.72 & Instability & Not Occurred & Possible \\
\hline 11.339 & 76.865 & 1.33 & 48.3 & 58.5 & 0 & 0.69 & Instability & Occurred & - \\
\hline 11.34 & 76.865 & 1.71 & 47.2 & 70.5 & 0 & 0.38 & Instability & Occurred & - \\
\hline 11.341 & 76.863 & 1.61 & 43.9 & 27.5 & 84 & 2.98 & Stability & Not Occurred & - \\
\hline 11.338 & 76.862 & 2.01 & 44.9 & 79.5 & 0 & 0.18 & Instability & Occurred & - \\
\hline 11.34 & 76.854 & 1.49 & 36.5 & 26.5 & 19 & 1.77 & Stability & Not Occurred & - \\
\hline 11.339 & 76.850 & 1.65 & 21.4 & 29.5 & 2 & 0.72 & Instability & Not Occurred & Possible \\
\hline 11.35 & 76.850 & 1.61 & 20.3 & 18.5 & 29 & 1.67 & Stability & Not Occurred & - \\
\hline 11.344 & 76.844 & 1.61 & 34.1 & 42.5 & 17 & 0.90 & Instability & Occurred & - \\
\hline 11.339 & 76.839 & 1.41 & 41.6 & 48.0 & 2 & 0.82 & Instability & Not Occurred & Possible \\
\hline 11.338 & 76.838 & 1.96 & 46.6 & 47.0 & 0 & 0.99 & Instability & Occurred & - \\
\hline 11.337 & 76.837 & 1.41 & 41.2 & 52.5 & 0 & 0.67 & Instability & Occurred & - \\
\hline 11.338 & 76.830 & 1.30 & 48.8 & 34.5 & 0 & 1.66 & Stability & Not Occurred & - \\
\hline 11.334 & 76.826 & 1.34 & 23.9 & 18.0 & 24 & 1.95 & Stability & Not Occurred & - \\
\hline 11.336 & 76.828 & 1.37 & 20.3 & 24.0 & 19 & 1.17 & Stability & Not Occurred & - \\
\hline 11.337 & 76.828 & 1.41 & 46.0 & 41.0 & 14 & 1.34 & Stability & Not Occurred & - \\
\hline 11.336 & 76.825 & 1.30 & 42.6 & 39.0 & 0 & 1.14 & Stability & Not Occurred & - \\
\hline 11.338 & 76.827 & 1.49 & 27.4 & 32.0 & 2 & 0.86 & Instability & Not Occurred & Possible \\
\hline 11.337 & 76.825 & 1.80 & 25.4 & 46.5 & 87 & 1.12 & Stability & Occurred & - \\
\hline 11.337 & 76.823 & 1.45 & 34.1 & 28.0 & 0 & 1.28 & Stability & Not Occurred & - \\
\hline 11.335 & 76.819 & 1.30 & 35.3 & 32.0 & 0 & 1.13 & Stability & Not Occurred & - \\
\hline 11.334 & 76.819 & 1.94 & 37.9 & 52.0 & 73 & 1.09 & Stability & Occurred & - \\
\hline 11.335 & 76.817 & 1.57 & 23.9 & 19.0 & 29 & 1.86 & Stability & Not Occurred & - \\
\hline 11.335 & 76.819 & 1.52 & 38.9 & 63.5 & 0 & 0.40 & Instability & Occurred & - \\
\hline 11.334 & 76.813 & 1.37 & 20.3 & 32.0 & 27 & 0.96 & Instability & Not Occurred & Possible \\
\hline 11.335 & 76.815 & 1.54 & 51.5 & 42.0 & 12 & 1.52 & Stability & Not Occurred & - \\
\hline 11.348 & 76.809 & 1.63 & 41.8 & 54.0 & 0 & 0.65 & Instability & Occurred & - \\
\hline 11.345 & 76.806 & 1.65 & 46.6 & 68.0 & 0 & 0.43 & Instability & Occurred & - \\
\hline
\end{tabular}

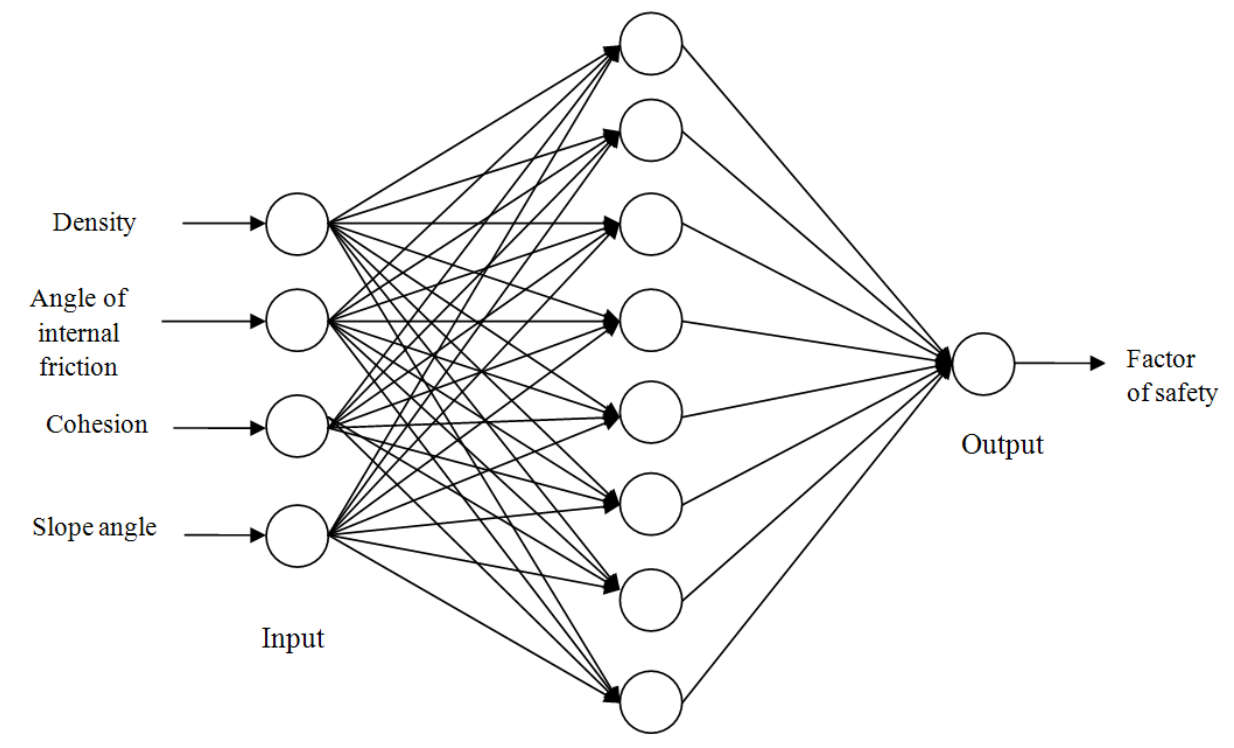

Hidden

Fig. 3. BP-ANN architecture 


\subsection{Artificial Neural Network}

Artificial Neural Network (ANN) is a widely used soft computing tool in the field of engineering research and it simulated with the human brain function artificially. It has the abilities of learning, adaptation, self-organization, decision making, function approximation and large-scale parallel processing. This neural network includes Back Propagation algorithm, genetic algorithm and ant colony algorithm. The back propagation learning algorithm is composed of forward propagation and Backward Propagation (BP-ANN). The neural network consists of input layer, output layer and one or more hidden layer in which neurons are linked to each other with changeable weight. The forward propagation transmits input signal to output layer through hidden layer. The backward propagation calculates the error between sample output and network output along with the original connection path, in the process of which the weights and thresholds of every layers are adjusted by the gradient descent method (Shahin et al., 2008; Jha et al., 2000).

The output of the network is compared with the value produced by the network to determine the error which is used to evaluate the performance of the network. The back propagation is used to identify slope stability analysis using Forward propagation and Back ward Propagation (BP-ANN) by many (Valdiya, 1998; Cruden, 1991; Naithani, 2007; Lin et al., 2009; Jiang et al., 2007; Cho, 2009; Abdalla et al., 2012). Therefore in slope stability, the soil parameters such as Density, Angle of internal friction, Cohesion and Slope angle obtained from the conventional method were trained in Neural Network (BP-ANN) using MATLAB version 2010a. The training was performed with $70 \%$ of sample and remaining $30 \%$ used as testing data for the prediction of factor of safety which is given in Table 1. Initially the dataset was normalized with $\mathrm{Z}$ score normalization. Density,
Angle of internal friction, Cohesion and Slope angle were the input layer; factor of safety was output layer and minimum error was achieved by trial eight neurons in hidden layer and training was performed.

It is found that there are vulnerable landslides possible in the Kallar-Coonoor hill road stretch. Soil samples from first 25 locations represented Table 1 were used to train the Neural Network (BP-ANN) and remaining 7 soil samples were used to test the trained network for prediction of factor of safety. In the present BP-ANN training, four input layers Density, Cohesion, Angle of internal friction and slope angle, Factor of Safety as one output layer and eight numbers of Hidden layers were set for continuous testing as shown in Fig. 3. Maximum training times-max epochs obtained in the training and testing was 50000 and the expected minimum error was 0.0001.The activation function used in the first layer was "tansig" the second layer was "purelin". The Back Propagation Artificial Neural Network (BP-ANN) training function is Levenberg Marquardt and the performance function was run with statistical indices such as mean square error. The results obtained in BP-ANN analysis is tabulated in Table 2.

\section{RESULTS}

The results of conventional analysis in the form of factor of safety for the selected 32 locations were presented in Table $\mathbf{1}$ and in this analysis, out of 32 locations, only 14 locations ensures stability in accordance to geometrical properties of slope and the geotechnical properties of the slope material. In the stable slopes, slope angles $(\beta)$ were observed to be less than the angle of shearing resistance. Slopes in the remaining 18 locations were recorded unstable and out of which, slopes in 14 locations were already affected by landslides.

Table 2. Comparison of BP-ANN output with conventional method results

\begin{tabular}{|c|c|c|c|c|c|}
\hline \multirow[b]{2}{*}{ Sample } & \multicolumn{2}{|c|}{ Conventional method } & \multicolumn{2}{|l|}{ BP-ANN results } & \multirow{2}{*}{$\begin{array}{l}\text { Physically observed } \\
\text { landslide }\end{array}$} \\
\hline & Factor of safety & Slope stability & Factor of safety & Slope stability & \\
\hline 1 & 1.09 & Stability & 0.9302 & Instability & Occurred \\
\hline 2 & 1.86 & Stability & 1.7219 & Stability & Not Occurred \\
\hline 3 & 0.4 & Instability & 1.0403 & Instability & Occurred \\
\hline 4 & 0.96 & Instability & 0.7962 & Instability & Not Occurred \\
\hline 5 & 1.52 & Stability & 1.5260 & Stability & Not Occurred \\
\hline 6 & 0.65 & Instability & 0.6528 & Instability & Occurred \\
\hline 7 & 0.43 & Instability & 0.4192 & Instability & Occurred \\
\hline
\end{tabular}


Nalina, P. et al. / Journal of Computer Science 10 (7): 1107-1114, 2014

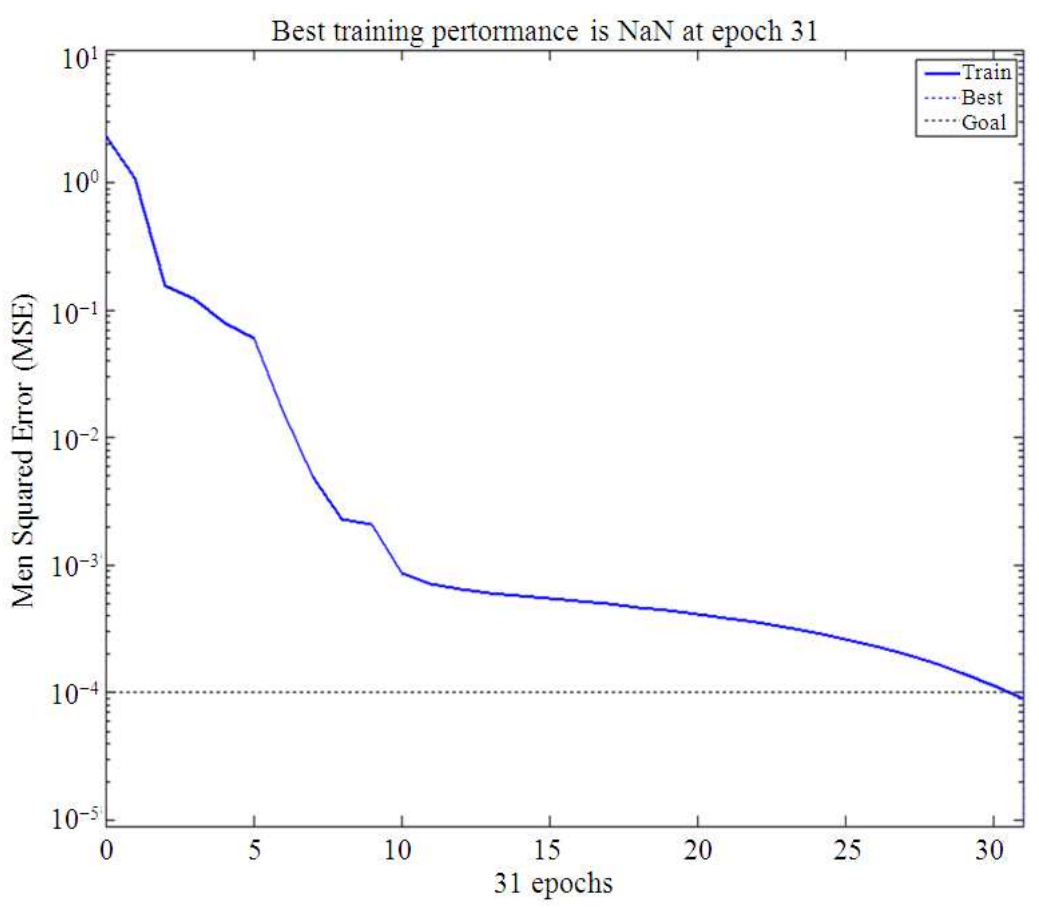

Fig. 4. BP-ANN Training performance graph (MSE Vs Epochs)

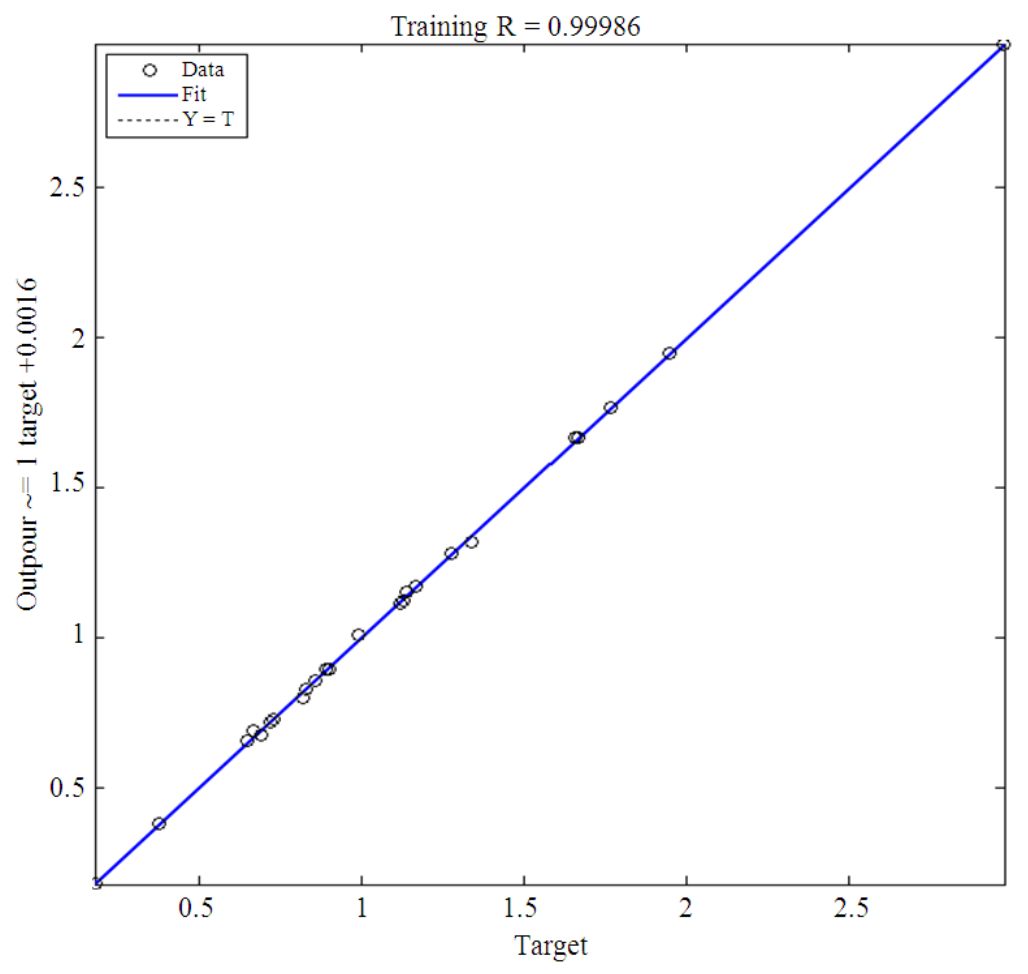

Fig. 5. Regression plot between target values Vs predicted values 
In the remaining 4 locations, the slopes are about to fail and which requires slope protection works at higher priority. Maximum and minimum factor of safety computed in the selected road stretch were 2.98 and 0.18 respectively. The reason for the instability being higher slope angle, hectic change in land cover, heavy monsoon rainfall, day-today increase in the traffic volume and uncemented geological nature of soil.

In the Back Propagation Neural Network Analysis (BPANN) using Levenberg Marquardt (Jha et al., 2000) training algorithm and mean square error performance algorithm, results of first 25 sample locations were used for training set and results of remaining 7 sample locations were used for validation of BP-ANN analysis. The BPANN training performance graph, Fig. 4 (MSE Vs Epochs) revealed that the Mean Square Error (MSE) stabilized at 0.0688 at 31 epochs. Figure 5 shows the regression plot between Target values and predicted values with $\mathrm{R}=$ 0.99986 , shows the level of accuracy of prediction.

\section{DISCUSSION}

The comparative results of conventional slope stability analysis and the BP-ANN analysis were furnished in Table 2. In the conventional method, results were obtained for particular location alone, whereas in BP-ANN method 25 location parameters were trained and based on the training output is shown for the remaining 7 locations. Comparison of these results indicates that the conventional method shows $71.4 \%$ accuracy, while in BP-ANN predicts the slope stability with $85.7 \%$ accuracy. The BP-ANN predicted factors of safety were closely matches with the factor of safety computed through the conventional method. Out of the 7 BP-ANN predictions, 6 predictions match with the previous history of landslide occurrences. Hence, the BP-ANN technique has been proved its applicability in slope stability predictions.

\section{CONCLUSION}

The Kallar-Coonoor hill road stretch is found highly vulnerable to landslide and slope protection measures are very much required in 18 locations. The reason for the landslide is being higher slope angle and heavy rainfall in monsoon. Since the area being in forest and hill slope, soft slope protection methods such as bioengineering may be of very much helpful for adaptation. It was also learnt from the present study that the hill slope of study area mainly constituted by the cohesion less soil, which provides more conducive environment to landslide occurrence especially during heavy rainfall. BP-ANN technique predicts the factor of safety against slope stability at an acceptable level of accuracy of $85.7 \%$ and the same has been reflected in its performance criteria. Therefore, it can be concluded that BP-ANN is a reliable technique to predict the factor of safety with site specific parametric limitations. Both conventional method and BP-ANN method proves good in stability prediction and validated with past landslide history. Presence of vegetation cover plays a significant role in slope protection but remains unincorporated in BP-ANN tool. Therefore vegetative cover should be improved to provide sustainable solution for slope stability.

\section{REFERENCES}

Abdalla, J.A., M. Atom and R. Hawileh, 2012. Artificial neural network prediction of factor of safety of slope stability of soils. Proceedings of the 14th International Conference on Computing in Cicvil and Building Engineering, Jun. 27-29, Moscow, Russia.

Ajaynaithani, K., V. Joshi and C. Prasad, 2002. Investigation on the impact of cloud burst in tehri district, Uttaranchal. J. Geol. Soc. India, 60: 573577.

Arora, D.S., 1988. A Text Book of Geology. 1st Edn., Mahindra Capital Publishers, Chandigarh.

Cho, S.E., 2009. Probabilistic stability analyses of slopes using the ANN based response surface. Comput. Geotechnics, 36: 787-797. DOI: 10.1016/j.compgeo.2009.01.003

Cruden, D.M., 1991. A simple definition of a landslide. IAEG Bull., 43: 27-29. DOI: 10.1007/BF02590167

Ganapathy, G.P., K. Mahendran and S.K. Seker, 2010. Need and urgency of landslide Rick planning for Nilgiri, Tamil Nadu, India. Int. J. Geomatics Geosci.

Gopalaranjan, A.S.R.and Rao, 1993. Basic and Applied Soil Mechanics. 1st Edn., Wiley, New Delhi.

GSI, 2000. District Resource Map Series: Nilgiri District Tamil Nadu, Geological Survey of IndiaXplanatory Note.

Jha, C.S., C.B.S. Dutt and K.S. Bawa, 2000. Deforestation and land use changes in Western Ghats, India. Curr. Sci., 79: 231-238.

Jiang, D., S. Xie, G. Li and Z. Jiang, 2007. Comparative analysis between Gray correlation degree and BP Neural Network on identifying slope stability. WestChina Exp. Eng., 12: 8-11. 
Kumar, S.V. and D.V.S. Bhagavanulu, 2008. Effect of deforestation on landslide in Nilgiris district. J. Indian Soc. Remote Sens., 36: 105-108. DOI: 10.1007/s12524-008-0011-5

Liang, H. and H. Zhang, 2012. Identification of slope stability based on the contrast of BP Neural Network and SVM. Proceedings of the 3rd IEEE International Conference on Computer Science and Information Technology, Jul. 9-11, IEEE Xplore Press, Chengdu, pp: 347-350. DOI: 10.1109/ICCSIT.2010.5564502

Lin, H.M., S.K.Chang, J.H. Wu and C.H.P. Juang, 2009. Neural network-based model for assessing failure potential of highway slopes in the Alishan, Taiwan Area: Pre-and post-earthquake investigation. Eng. Geol., 104: 280-289. DOI: 10.1016/j.enggeo.2008.11.007

Manimaran, G., A.A. Ravindaran, S. Selvam, D. Manimaran and M. Sugan, 2012. Characterization and disaster management of Landslides in the Nilgiris mountainous terrain of Tamil Nadu, India. Int. J. Geomat. Geosci., 3: 1-12.
Naithani, A.K., 2007. Macro landslide hazard zonation mapping using univariate statistical analysis in a part of Garhwal Himalaya. J. Geol. Soc. India, 70: 282-296.

Neaupane, K.M. and S.H. Achet, 2004. Use of back propagation neural network for landslide monitoring: A case study in the higher Himalaya. Eng. Geol., 74: 213-326. DOI: 10.1016/j.enggeo.2004.03.010

Ramasamy, S.M., R. Neelakantan and S. Francis, 2006. Predictive and Preventive modeling for landslide in the Nilgiris, South India using remote sensing and GIS. A Perception and Initiatives of DST, Landslides, pp: 177-203.

Shahin, M.A., M.B. Jaksa and H.R. Maier, 2008. State of art of artificial neural networks in geotechnical engineering. Electr. J. Geotechnical Eng.

Terzaghi, K. and R.B. Peck, 1967. Soil mechanics in Engineering Practice. 2nd Edn., Wiley, New York, ISBN-10: 0471852732, pp: 729.

Valdiya, K.S., 1998. Catastrophic landslides in uttaranchal, central Himalaya. J. Geol. Soc. India, 52: 483-486. 